\title{
Overexpression of Ephrin A2 receptors in cancer stromal cells is a prognostic factor for the relapse of gastric cancer
}

\author{
Shojiro Kikuchi $\cdot$ Nobuaki Kaibe $\cdot$ Koji Morimoto $\cdot$ Hirokazu Fukui $\cdot$ \\ Hirotaka Niwa - Yoshihiro Maeyama - Masashi Takemura • Masaki Matsumoto • \\ Shoji Nakamori · Hiroto Miwa $\cdot$ Seiichi Hirota $\cdot$ Mitsuru Sasako
}

Received: 6 February 2014/ Accepted: 15 May 2014/Published online: 8 June 2014

(c) The International Gastric Cancer Association and The Japanese Gastric Cancer Association 2014

\begin{abstract}
Background Microenvironments control cancer growth and progression. We explored the prognostic impact of stromal reaction and cancer stromal cells on relapse risk and survival after curative gastrectomy in gastric cancer patients.

Methods Tissue samples were obtained from 107 patients with gastric adenocarcinoma who underwent curative (R0) gastrectomy. Primary stromal cells isolated from gastric cancer tissue (GCSC) and normal gastric tissue (Gastric stromal cell: GSC) in each patient were cultured and subjected to comprehensive proteome (LC-MS/MS) and realtime RT-PCR analysis. Expression of Ephrin A2 receptors (EphA2) in cancers and GCSC was evaluated immunohistochemically. Intermingling of EphA2-positive cancer cells and GCSC (IC/A2+) and overexpression of EphA2 in cancer cells $(\mathrm{Ca} / \mathrm{A} 2+)$ in invasive parts of tumors were assessed, as were relationships of IC/A2+, $\mathrm{Ca} / \mathrm{A} 2+$, and
\end{abstract}

S. Kikuchi and N. Kaibe contributed equally to this work.

Electronic supplementary material The online version of this article (doi:10.1007/s10120-014-0390-y) contains supplementary material, which is available to authorized users.

S. Kikuchi $(\bowtie) \cdot$ N. Kaibe $\cdot$ H. Niwa · Y. Maeyama •

M. Takemura · M. Sasako

Department of Surgery, Hyogo College of Medicine, 1-1

Mukogawa-cho, Nishinomiya, Hyogo 663-8501, Japan

e-mail: skikuchi@hyo-med.ac.jp

K. Morimoto

Department of Breast and Endocrine Surgery, Osaka University,

Osaka, Japan

H. Fukui · H. Miwa

Department of Medicine, Hyogo College of Medicine,

Nishinomiya, Japan clinicopathological factors with relapse-free survival and overall survival.

Results Proteome analysis showed that EphA2 expression was significantly higher in GCSC than GSC. Real-time RTPCR analysis showed that levels of EphA1/A2/A3/A5 and EphB2/B4 were $\geq 2.0$-fold higher in GCSC than GSC. Ca/ A2 and IC/A2 were positive in $65(60.7 \%)$ and 26 $(24.3 \%)$ patients, respectively. Relapse was significantly more frequent in IC/A2-positive than in IC/A2-negative (HR, 2.12; $95 \%$ CI, 1.16-5.41; $p=0.0207$ ) patients. Among the 54 patients who received S-1 adjuvant chemotherapy, relapse-free survival (RFS) was significantly shorter in those who were IC/A2-positive than in those who were IC/A2-negative and Ca/A2-negative (HR, 2.83; $95 \%$ CI, $1.12-12.12 ; p=0.0339)$. Multivariable analysis indicated that pathological stage $(p=0.010)$ and IC/A2+ $(p=0.008)$ were independent risk factors for recurrence. Conclusion IC/A2+ was predictive of relapse after curative (R0) gastrectomy.

Keywords EphA2 - Gastric cancer - Stromal reaction Predictive marker - Cancer-associated fibroblasts

\author{
M. Matsumoto \\ Department of Molecular and Cellular Biology, Medical Institute \\ of Bioregulation, Kyushu University, Fukuoka, Japan \\ S. Nakamori \\ Department of Surgery, Osaka National Hospital, Osaka, Japan \\ S. Hirota \\ Department of Pathology, Hyogo College of Medicine, \\ Nishinomiya, Japan
}




\section{Introduction}

Gastric cancer is the second leading cause of cancer deaths in both sexes worldwide (736,000 deaths, $9.7 \%$ of the total). Sufficient surgical resection plus regional lymph node dissection in experienced centers have been shown to significantly improve overall survival (OS). Complete resection of the primary tumor and any local spread, including lymph node metastasis, is essential for cure. Other therapeutic approaches, such as chemotherapy, hormonal therapy, and radiotherapy, are insufficiently effective in preventing tumor recurrence. Combination chemotherapy regimens consisting of two or three cytotoxic agents results in an OS of 10-13 months in patients with unresectable or metastatic gastric cancer [1, 2]. Some patients who undergo R0 (curative) resection followed by postoperative therapy experience tumor relapse. At present, only tumor node metastasis (TNM) classification is predictive of relapse after adjuvant treatment.

Erythropoietin-producing hepatocellular (Eph) receptors are novel targets for anti-cancer agents, because EphA2 is frequently overexpressed in a variety of human epithelial cancer [3-5]. This overexpression is often associated with an aggressive tumor phenotype [6,7]. Eph receptors are the largest known family of receptor tyrosine kinases (RTKs), and are activated by interacting with cell-surface ligands, termed ephrins. Eph receptors are classified into A-type (EphA1-8 and EphA10) and B-type (EphB1-4 and EphB6) based on their interactions with ephrin ligands, which are also classified as A-type and B-type. Eph receptors and ephrin ligands control cell morphology, adhesion, migration, and invasion by modifying the organization of the actin cytoskeleton and influencing the activities of integrins and intercellular adhesion molecules in bidirectional signaling pathways [8].

Cancer tissue is composed of cancer cells and stromal cells such as fibroblasts, monocyte/macrophages, endothelial cells, and immune cells (lymphocytes and neutrophils). Cancer progression is not solely determined by the cancer cells themselves, but also by the surrounding stromal cells [9-15.] We found that EphA2 was locally overexpressed in both cancer cells and gastric cancer tissue (GCSC) in invasive parts of tumors, but the function of EphA2 in these cells is still unclear. We therefore assessed the prognostic impact of stromal reaction and EphA2 expression in cancer cells and GCSC. To our knowledge, this study is the first to assess whether EphA2 overexpression in GCSC is predictive of the risk of relapse after curative gastrectomy in patients with gastric cancer.

\section{Methods}

\section{Patients}

We retrospectively analyzed findings in 107 patients who underwent curative (R0) resection of primary gastric adenocarcinoma at Hyogo College of Medicine, Japan, between 2008 and 2010. Patients were included if they had histologically proven T2-T4b gastric cancer; had undergone R0 resection with D2 or more extensive lymph-node dissection; had no distant metastases or tumor cells on peritoneal lavage cytology; and did not receive treatment prior to surgery. Following surgery, 79 patients $(73.8 \%)$ were eligible for adjuvant chemotherapy, and 54 patients $(50.5 \%)$ received adjuvant chemotherapy without severe adverse effects, consisting of $80 \mathrm{mg} / \mathrm{m}^{2} \mathrm{~S}-1$ (tegafur-gimeracil-oteracil potassium) administered orally on days 1-28 every 6 weeks, for eight cycles. The median followup period was 1,279 days (range 163-2,106 days). During the study, 13 patients died from gastric cancer relapse and five from other causes. Tumor recurrence was observed in 39 patients, including 15 with blood-borne, 14 with peritoneal, six with lymph node, and four with other types of recurrence. Patients were followed up monthly for the first year and every 3 months thereafter. Relapse was determined by imaging modalities, including ultrasonography, computed tomography (CT, performed every 3-6 months), gastrointestinal radiography, endoscopy, positive emission tomography/CT scan, blood tests (every 1-3 months) and ascites cytology.

\section{Study design and treatment}

The study protocol was approved by the Institutional Medical Ethics Committees of Hyogo College of Medicine. Written informed consent was obtained from all patients. The primary endpoint was relapse-free survival (RFS) and overall survival (OS). Clinicopathological data on all patients were collected prospectively. Tumors were classified according to the TNM system of the International Union Against Cancer (UICC), 7th edition, and the Japanese Classification of Gastric Carcinoma, 14th edition [16].

\section{Pathological classification and IC}

Formaldehyde (10\%)-fixed and paraffin-embedded specimens of surgically resected samples were used for hematoxylin-eosin (HE) staining and immunohistochemistry. All samples were histologically analyzed by a pathologist, to determine pathological diagnosis and intermingling of scattered cancer cells and GCSC (IC), with or without EphA2 expression. ICs were defined as (1) scattered cancer cells intermingled with GCSC in invasive parts of tumors; and (2) staining for EphA2 in cancer cells or GCSC that was equal to or stronger than in the soma of Auerbach's plexus, in which EphA2 is normally expressed. ICs positive and negative for EphA2 expression in invasive parts of tumors were designated IC/A2+ and IC/A2-, respectively. IC/A2 consists of double-positive cancer cells and GCSC 
in invasive parts of tumor. EphA2 staining of $>50 \%$ of cancer cells throughout the tumor was designated as $\mathrm{Ca} /$ $\mathrm{A} 2+$. We analyzed the cancer-stromal mixture in 107 cases, but we couldn't find any case of EphrinA2-positive only in GCSC and not in cancer cells. Although gastric cancer has been defined as intestinal and diffuse types, most of these tumors consisted of heterogeneous tissue. If the pathological type of the major and invasive parts of the tumor differed, the tumor was defined as transitional type.

Primary cultured stromal cells

Following resection, tissue samples were prepared from cancerous lesions (GCSC) and non-cancerous areas at least $50 \mathrm{~mm}$ removed from the tumor (GSC). The specimens were trimmed of fat and necrotic tissues, minced, and transferred to 12-well microplates. Cells were cultured in Dulbecco's modified Eagle's medium (GIBCO, Grand Island, NY) supplemented with $10 \%$ fetal calf serum. Isolated fibroblasts were transferred to other dishes and used for experiments within eight passages.

Proteome analysis of stromal cells

\section{Liquid chromatography-tandem mass spectrometry (LC- MS/MS analysis)}

Sample preparation for $L C-M S / M S$ analysis Stromal cells $(2 \times 10 \mathrm{e} 6$ cells $)$ were lysed in $100 \mathrm{mM}$ Tris-HCl, pH 8.8, $7 \mathrm{M}$ urea, $2 \%$ SDS. Cell lysates were sonicated using Bioraptor and subjected to protein assay (BCA method) and clarified by centrifugation for $20 \mathrm{~min}$ at $13,500 \mathrm{rpm}$. Proteins $(200 \mathrm{mg}$ ) were then precipitated using methanolchloroform, resuspended in a buffer containing $7 \mathrm{M}$ guanidium hydroxide in $0.5 \mathrm{M}$ triethylammonium hydrogen

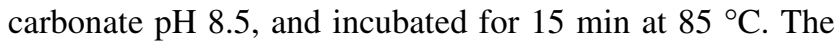
sample was diluted with fourfold volumes of water and digested with Lys-C at $37{ }^{\circ} \mathrm{C}$ for $4 \mathrm{~h}$; this was followed by twofold dilution and trypsin digestion at $37{ }^{\circ} \mathrm{C}$ overnight (enzyme-to-protein ratio of 1:100 [w/w]). After reduction with $0.625 \mathrm{mM}$ TCEP and alkylation with $3.125 \mathrm{mM}$ iodoacetamide (IAA), digests were stored at $-80{ }^{\circ} \mathrm{C}$ until analysis.

$L C-M S / M S$ analysis All samples were analyzed by $\mathrm{Q}$ Exactive (Thermo Fisher Scientific), equipped with an AdvanceLC HPLC pump and HTC-PAL autosampler (CTC Analytics AG, Zwingen, Switzerland). L-column C18 materials ( $3 \mu \mathrm{m}$, CERI Japan) were packed into selfpulled fused silica capillaries $(100 \mu \mathrm{m}$ inner diameters, $20 \mathrm{~cm}$ length) by using a high pressure chamber equipped with an HPLC pump at constant pressure of 230 bar. All samples were dissolved in $0.1 \%$ TFA, $2 \%$ acetnitrile, and injected to pre-column (L-column micro: $0.3 \mathrm{~mm}$ inner diameter, $5 \mathrm{~mm}$ length, CERI Japan), washed with the same buffer, and eluted with a linear gradient of 5-35\% B for $90 \mathrm{~min}, 35-95 \% \mathrm{~B}$ for $1 \mathrm{~min}$, and $95-95 \% \mathrm{~B}$ for 10 min (A: $0.1 \%$ formic acid, $2 \%$ acetonitrile, B: $0.1 \%$ formic acid, $90 \%$ acetnitrile) at a flow rate of $200 \mathrm{nl} / \mathrm{min}$. The $\mathrm{Q}$ Exactive was operated in the data-dependent mode with survey scans acquired at a resolution of 70,000 at $\mathrm{m} /$ $z$ 200. The top ten most abundant ions were selected with an isolation window of 1.5 Thomsons and fragmented by higher energy collisional dissociation with normalized collision energies of 35 . The ion target values were set to 1 e6 for survey scan and 5e5 for MS/MS scan, respectively. The maximum ion injection times for both survey scan and MS/MS scan were $60 \mathrm{~ms}$. Dynamic exclusion times was 60 s. Fibroblasts $\left(2 \times 10^{6}\right.$ cells $)$ were lysed and sonicated. Following the determination of protein concentrations using the bicinchoninic acid method, $200 \mathrm{mg}$ proteins were denatured and digested. All samples were analyzed by liquid chromatography-tandem mass spectrometry (LCMS/MS), using Q Exactive (Thermo Fisher Scientific), equipped with an AdvanceLC HPLC pump and HTC-PAL autosampler (CTC Analytics AG, Zwingen, Switzerland). L-Column C18 materials ( $3 \mu \mathrm{m}$, CERI Japan) were packed into self-filling fused silica capillaries using a high pressure chamber equipped with an HPLC pump. The Q Exactive was operated in the data-dependent mode with survey scans. The ten most abundant ions were selected with an isolation window and fragmented by higher energy collisional dissociation with normalized collision energies. The ion target values were set to survey scan and MS/MS scan, respectively.

\section{Real-time RT-PCR and RNA microarray of stromal cells}

Total RNA was extracted from three sets of CAFs and NGFs using Trizol reagent (Gibco BRL, Rockville, MD). Real-time RT-PCR analysis were performed according manufacture's protocol (Power SYBR ${ }^{\circledR}$ Green PCR, applied biosystems, Warrington, UK) using Ephrin primers (Supplementary Table 1) by ABI SDS-7900HT (ABI). For RNA Microarray analysis, synthesis of cRNA, hybridization, scanning and data analysis were performed by Hokkaido System Science Co., Ltd. (Sapporo, Japan). Briefly, cyanine-3 (Cy3) labeled cRNA was prepared from total RNA $(0.05 \mu \mathrm{g})$ using the Low Input Quick Amp Labeling Kit (Agilent) according to the manufacturer's instructions. These Cy3-labeled cRNAs $(0.60 \mu \mathrm{g})$ were fragmented and hybridized to Agilent SurePrint G3 Human Gene Expression Microarrays $(8 \times 60 \mathrm{~K}$ ver.2.0). All fibroblast samples were assayed in triplicate. Those samples on the microarrays that showed significantly different expression when hybridized with labeled cRNA from GCSC and GSC 
Table 1 Proteome analyses of GCSC and GCS, performed by LC-MS/MS procedure

\begin{tabular}{|c|c|c|c|c|c|c|c|}
\hline Gene symbol & Description & $\begin{array}{l}\text { Ratio } \\
\text { (GSC) }\end{array}$ & SD & $P$ value & $\begin{array}{l}\text { Ratio } \\
\text { (GCSC/ } \\
\text { GSC) }\end{array}$ & SD & $P$ value \\
\hline \multicolumn{8}{|l|}{ Experiment\#1 } \\
\hline TRPV2 & $\begin{array}{l}\text { (ref_NP_057197 Gl:20127551) TRANSIENT RECEPTOR } \\
\text { POTENTIAL CATION CHANNEL_SUBFAMILY V }\end{array}$ & 1 & 3.464 & $1.00 \mathrm{E}+00$ & 140.118 & 248.059 & $1.43 \mathrm{E}-09$ \\
\hline KRI8 & (spr_K2C8_HUMAN P05787) KERATIN 8 & 1 & 1.511 & $1.00 \mathrm{E}+00$ & 7.590 & 6.476 & $2.91 \mathrm{E}-06$ \\
\hline N/A & (ens_P00000346026) \#\#\#_NO_DESCRIPTION_\#\#\# & 1 & 1.511 & $1.00 \mathrm{E}+00$ & 7.590 & 6.476 & $2.91 \mathrm{E}-06$ \\
\hline N/A & (tre_Q8NAB7) HYPOTHETICAL PROTEIN FLJ3563S & 1 & 0.231 & $1.00 \mathrm{E}+00$ & 6.586 & 1.241 & $4.95 \mathrm{E}-08$ \\
\hline POSTN & $\begin{array}{l}\text { (Spr_POSN_HUMAN Q15063_2) SPLICE ISOFORM } 2 \text { OF } \\
\text { Q15063 PERIOSTIN PRECURSOR }\end{array}$ & 1 & 0.074 & $1.00 \mathrm{E}+00$ & 6.189 & 0.485 & $2.00 \mathrm{E}-15$ \\
\hline MIPS & $\begin{array}{l}\text { (tre_Q72525) D_MYO_INOSITOL_3_PHOSPHATE } \\
\text { SYNTHASE }\end{array}$ & 1 & 0.458 & $1.00 \mathrm{E}+00$ & 2.773 & 0.887 & $3.64 \mathrm{E}-11$ \\
\hline KRT15 & $\begin{array}{l}\text { (spt_K1CO_HUMAN P19012) KERATIN_TYPE } 1 \\
\text { CYTOSKELETAL } 15\end{array}$ & 1 & 0.237 & $1.00 \mathrm{E}+00$ & 2.609 & 0.415 & $6.74 \mathrm{E}-05$ \\
\hline LOX & $\begin{array}{l}\text { (spt_LYOX_HUMAN P28300) PROTEIN_LYSINE } \\
\text { 6_OXIDASE PRECURSOR }\end{array}$ & 1 & 0.039 & $1.00 \mathrm{E}+00$ & 2.411 & 0.126 & $9.90 \mathrm{E}-20$ \\
\hline PPME1 & $\begin{array}{c}\text { (spr_PME1_HUMAN Q9Y570_2) SPLICE ISOFORM } 2 \text { OF } \\
\text { Q9Y570 PROTEIN PHOSPHATASE METHYLESTER }\end{array}$ & 1 & 0.215 & $1.00 \mathrm{E}+00$ & 2.254 & 0.402 & $8.17 \mathrm{E}-06$ \\
\hline ЕРНA2 & $\begin{array}{l}\text { (spr_EPA2_HUMAN P29317) EPHRIN TYPE_A } \\
\text { RECEPTOR } 2 \text { PRECURSOR }\end{array}$ & 1 & 0.312 & $1.00 \mathrm{E}+00$ & 2.221 & 0.484 & $5.70 \mathrm{E}-04$ \\
\hline ANXA3 & (spr_ANX3_HUMAN P12429) ANNEXIN A3 & 1 & 0.080 & $1.00 \mathrm{E}+00$ & 2.217 & 0.217 & $9.90 \mathrm{E}-20$ \\
\hline PCDH12 & $\begin{array}{l}\text { (spr_PC12_HUMAN Q9NPG4) PROTOCADHERIN } 12 \\
\text { PRECURSOR }\end{array}$ & 1 & 0.307 & $1.00 \mathrm{E}+00$ & 2.177 & 0.478 & $7.23 \mathrm{E}-08$ \\
\hline N/A & (tre_Q9HBQ4) HYPOTHETICAL PROTEIN & 1 & 0.031 & $1.00 \mathrm{E}+00$ & 2.149 & 0.117 & $8.19 \mathrm{E}-08$ \\
\hline N/A & $\begin{array}{l}\text { (ref_NP_004872 GI22538444) QUINONE } \\
\text { OXIDOREDUCTASE HOMOLOG }\end{array}$ & 1 & 0.278 & $1.00 \mathrm{E}+00$ & 2.111 & 1.250 & $1.43 \mathrm{E}-01$ \\
\hline MFGE8 & $\begin{array}{l}\text { (spr_MFGM_HUMAN Q08431) LACTADHERIN } \\
\text { PRECURSOR }\end{array}$ & 1 & 0.252 & $1.00 \mathrm{E}+00$ & 2.027 & 0.325 & $3.23 \mathrm{E}-09$ \\
\hline EDIL3 & $\begin{array}{l}\text { (spr_E0I3_HUMAN 0438S4_2) SPLICE ISOFORM } 2 \text { OF } \\
\text { 0438S4 EGF_LIKE REPEATS AND DISCOIDIN }\end{array}$ & 1 & 0.463 & $1.00 \mathrm{E}+00$ & 2.020 & 0.565 & $2.18 \mathrm{E}-03$ \\
\hline \multicolumn{8}{|l|}{ Experiment\#2 } \\
\hline TNFRSF11B & $\begin{array}{l}\text { (spr_T11B_HUMAN 000300) TUMOR NECROSIS } \\
\text { FACTOR RECEPTOR SUPERFAMILY MEMBER 11B } \\
\text { PRECUR }\end{array}$ & 1 & 0.808 & $1.00 \mathrm{E}+00$ & 32.112 & 15.504 & $9.90 \mathrm{E}-20$ \\
\hline EPHA5 & $\begin{array}{l}\text { (spr_EPA5_HUMAN P54756_2) SPLICE ISOFORM } 2 \text { OF } \\
\text { P54756 EPHRIN TYPE_A RECEPTOR } 5 \text { PRECUR }\end{array}$ & 1 & 1.934 & $1.00 \mathrm{E}+00$ & 10.610 & 13.107 & $7.70 \mathrm{E}-04$ \\
\hline CHRM2 & $\begin{array}{l}\text { (spr_ACM2 HUMAN P08172) MUSCARINIC } \\
\text { ACETYLCHOLINE RECEPTOR M2 }\end{array}$ & 1 & 0.970 & $1.00 \mathrm{E}+00$ & 8.709 & 6.770 & $4.71 \mathrm{E}-05$ \\
\hline ЕРНА2 & $\begin{array}{l}\text { (spr_EPA2 HUMAN P293I7) EPHRIN TYPE_A } \\
\text { RECEPTOR } 2 \text { PRECURSOR }\end{array}$ & 1 & 0.111 & $1.00 \mathrm{E}+00$ & 4.967 & 0.546 & $3.14 \mathrm{E}-14$ \\
\hline PVR & $\begin{array}{l}\text { (spr_PVR.HUMAN P15151_4) SPLICE ISOFORM DELTA } \\
\text { OF P15I5I POLIOVIRUS RECEPTOR PRECURSO }\end{array}$ & 1 & 0.284 & $1.00 \mathrm{E}+00$ & 3.370 & 1.298 & $4.55 \mathrm{E}-15$ \\
\hline
\end{tabular}

EphA2 was upregulated 2.221-fold (experiment \#1) and 4.967-fold (experiment \#2). EphA5 was upregulated 10.610-fold in experiment \#2, and keratins 8 and 15 and lysine-6-oxidase were upregulated in experiment \#1. Taken together, these findings suggest that re-organization of the cytoskeleton and extracellular matrix, including collagens, was activated in GCSC

were quantified using the peak area of precursor ion extracted at $5 \mathrm{ppm}$ tolerance.

Antibodies and immunohistochemistry

Formalin-fixed, paraffin-embedded tissue samples were cut $3 \mu \mathrm{m}$ thick using the Ventana BenchMark XT system
(Ventana Medical Systems, Tucson, AZ, USA). After antigen retrieval and quenching by immersion in $3 \%$ hydrogen peroxide, the tissue sections were incubated with primary antibodies (Abs) to EphA2 (Santa Cruz Biotechnology; Santa Cruz, CA, USA), pan-keratin (AE1/AE3; clone PCK26), $\alpha$-smooth muscle actin ( $\alpha$-SMA; clone $1 \mathrm{~A} 4)$ and vimentin (clone V9) (all from Roche; Basel, 
Switzerland), and D2-40 (podoplanin, 760-4395, CELL MARQUE; Rocklin, CA, USA). Binding was detected using the iVIEW DAB Universal Kit, according to the manufacturer's instructions, and all sections were counterstained with hematoxylin.

\section{Statistical analysis}

The $\chi^{2}$ test was used to analyze possible associations of Eph receptor expression with clinicopathological variables. RFS was calculated using the Kaplan-Meier method and compared using the log-rank test. Multivariate proportional Cox models were used to assess the prognostic significance of factors on RFS. $P$ values less than 0.05 were considered statistically significant. All statistical analyses were performed using IBM SPSS Statistics 19 software (IBM Inc., Armonk, NY, USA).

\section{Results}

Proteome analysis and expression analysis of stromal cells

Proteome analyses were performed using LC-MS/MS methods. Upregulated peptides (GCSC/GSC ratios $>2.0$, $p<0.05$ ) are shown in Table 1. Interestingly, only 16 and six peptides were upregulated in GCSC in experiments 1 and 2, respectively. EphA2 was upregulated in these two experiments 2.221-fold and 4.967-fold, respectively. EphA5 was upregulated 10.610-fold in experiment 2, whereas keratins 8 and 15 and lysine-6-oxidase were upregulated in experiment 1.

Real-time RT-PCR analysis showed that EphA1, EphA2, EphA3, EphA5, EphB2, and EphB4 were upregulated 3.50-, 4.76-, 2.36-, 3.57-, 2.93-, and 2.86-fold, respectively, in GCSC relative to GSC in each patient (Fig. 1). Quantitative RNA microarray analysis of the levels of expression of all isoforms of the ephrin family showed that EphA2 and EphB2 were upregulated 2.28-fold and 2.22-fold, respectively, in GCSC relative to GSC in each patient. The GCSC/GSC expression ratios of other ephrin receptor isoforms ranged from 0.5 to $2.0(n=3)$. All sets of fibroblasts were obtained from diffuse-type gastric cancers (Supplementary Figure 1).

Immunohistochemistry

Scattered cancer cells and stromal cells, mostly consisting of fibroblasts, formed intermingled complexes in the invasive part of transitional-type tumors (Fig. 2a) and in all parts of diffuse-type tumors (Fig. 2c). Expression of EphA2 was observed in both cancer cells and GCSC

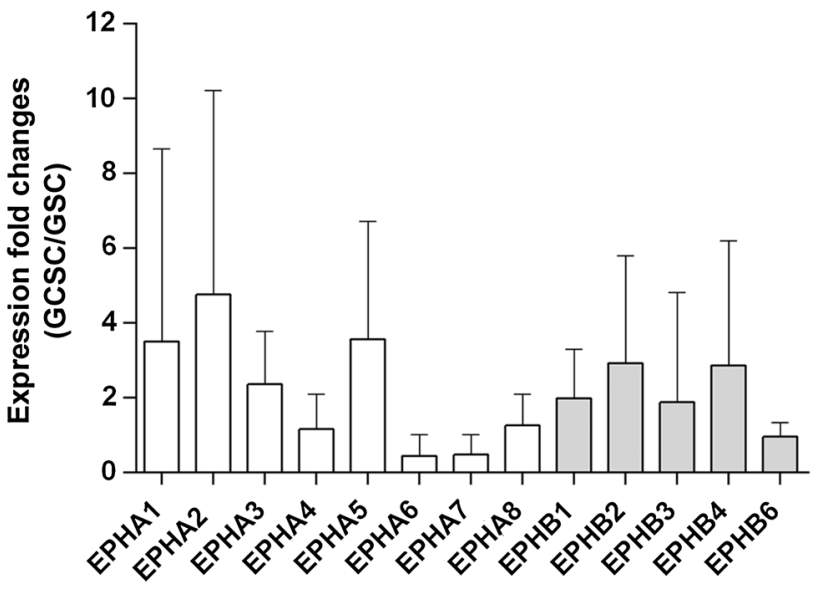

Fig. 1 Real-time RT-PCR analysis of Ephrin receptors of GCSC and GSC. Real-time RT-PCR analysis showed that EphA1, EphA2, EphA3, EphA5, EphB2, and EphB4 were upregulated 3.50-, 4.76-, 2.36-, 3.57-, 2.93-, and 2.86-fold, respectively, in GCSC relative to GSC in each patient. But there was no significance. All sets of stromal cells were obtained from diffuse-type gastric cancers $(n=6)$

(brown, Fig. 2b, d). IC/A2+ in intestinal- type, transitional type tumors were mostly located at the extremities of the invasive parts. Cancer cells and GCSC expressed EphA2 (Fig. 3a, b). GCSC in ICs appeared as large or small in shape. EphA2 was normally expressed in the soma of Auerbach's plexus (Fig. 3h, black arrows). Keratin expression was observed in cancer cells, whereas vimentin expression was observed in GCSC, endothelial cells, and hematopoietic cells (Fig. 3c, d). Although cultured activated fibroblasts were believed to overexpress $\alpha$-SMA, we found that large GCSC expressed $\alpha$-SMA (Fig. 3e, asterisks), whereas most small-shaped GCSC in ICs did not (Fig. 3e). Large populations of EphrinA2-positive GCSC in IC were vimentin-positive (Fig. 3d), and keratin-, $\alpha$ SMA-, CD31-, D2-40-negative (Fig. 3c, e, f, g). We examine double immunofluorescent staining with $\alpha$-SMA (green) and EphA2 (red) in Fig. 4. In the left panel, all GCSC looks EphrinA2-positive and one cell strongly expressed $\alpha$-SMA (white arrow head). In the right panel, all GCSC were EphA2 negative and some population of GCSC was $\alpha$-SMA-positive (green, white arrow head). Primary cultured GCSC expressed different levels of $\alpha$ SMA, and some populations strongly expressed $\alpha$-SMA. These data suggest that the status of GCSC in IC/A2+ might be different from that in cultured and activated myofibroblasts.

Prognostic significance of $\mathrm{Ca} / \mathrm{A} 2$ and IC/A2

IC/A2 \pm and $\mathrm{Ca} / \mathrm{A} 2+$ were found in $26(24.3 \%)$ and 65 $(60.7 \%)$ of the 107 patients, respectively (Supplementary 
Fig. 2 Intermingling of scattered cancer cells and GCSC (IC). ICs were defined as 1) scattered cancer cells intermingled with GCSC in invasive parts of tumors; and 2) staining for EphA2 in cancer cells or GCSC being equal to or stronger than in the soma of Auerbach's plexus, in which EphA2 is normally expressed. ICs in transitional type (a, b) and diffuse type (c, d) gastric cancers. (a, c, HE staining; b, d, EphA2 staining). Original magnification $\times 20$
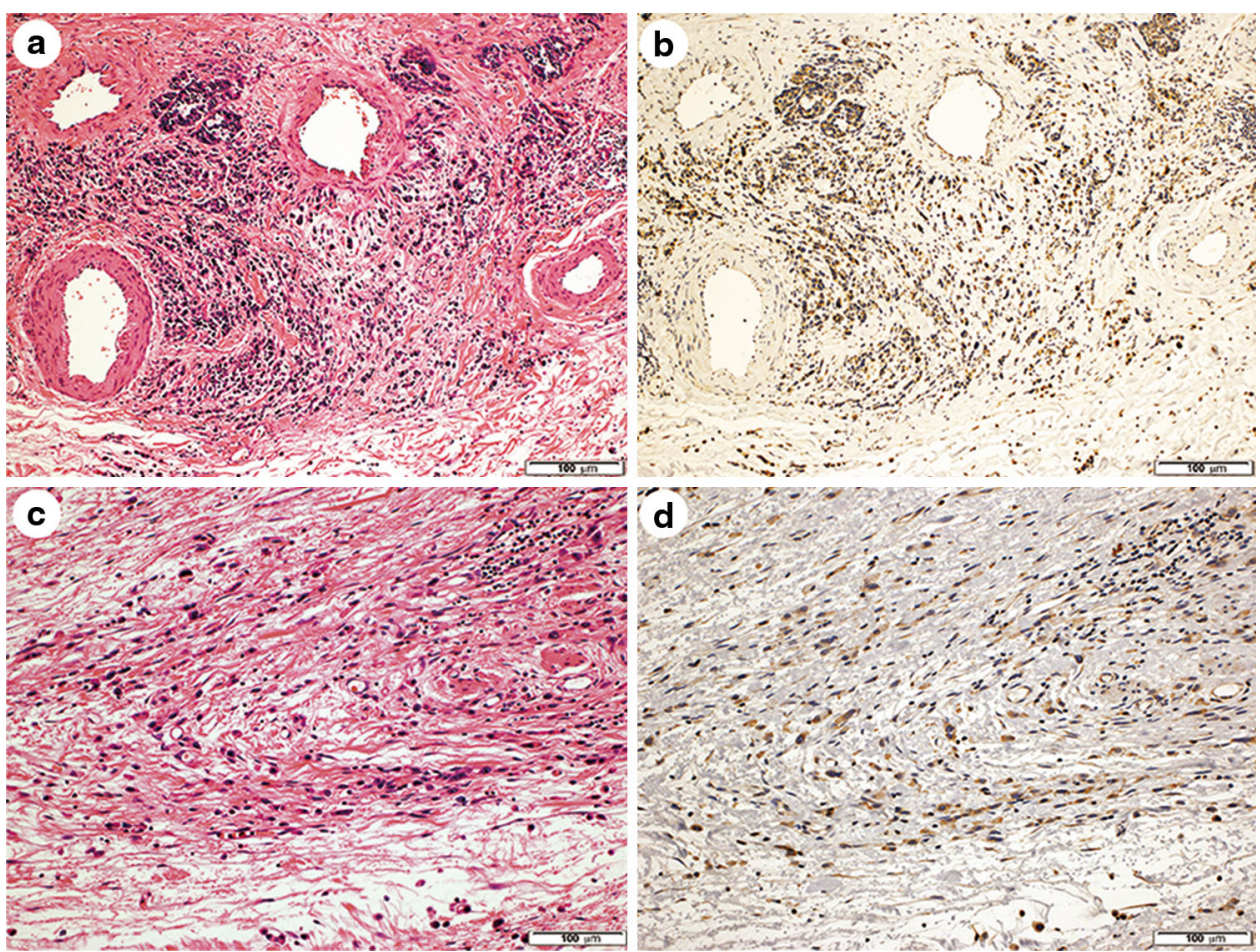

Table 2). The relapse rate was significantly higher in IC/ $\mathrm{A} 2+$ than in IC/A2 - patients, with 14 of 26 IC/A2+ $(53.8 \%)$ patients relapsing after a median 347 days [hazard ratio (HR), 2.12; $95 \%$ CI, 1.16-5.41; $p=0.0207$, Fig. 5a]. Similarly, the relapse rate was higher in patients classified as $\mathrm{Ca} / \mathrm{A} 2+$ than as $\mathrm{Ca} / \mathrm{A} 2-[\mathrm{HR}, 1.96 ; 95 \% \mathrm{CI}$, $0.99-3.51 ; p=0.0542]$, with 28 of $65(43.1 \%) \mathrm{Ca} / \mathrm{A} 2+$ patients developing recurrence at a median 302 days (Fig. 5b). Overall survival was similar in IC/A2- and Ca/ A2 positive or negative patients (Fig. 6a, b).

Prognostic significance of $\mathrm{Ca} / \mathrm{A} 2$ and IC/A2 in patients who received adjuvant chemotherapy

Although $\mathrm{Ca} / \mathrm{A} 2+$ was not significantly prognostic in patients who received adjuvant chemotherapy (Figs. 4d, $5 \mathrm{~d}), \mathrm{IC} / \mathrm{A} 2+$ was significantly associated with poorer RFS during adjuvant chemotherapy (HR, 3.00; $95 \%$ CI, $1.47-17.03 ; p=0.0108$, Fig. $5 c)$. Stromal reaction may have been prognostic, because patients classified as IC/ $\mathrm{A} 2+$ had significantly reduced median RFS than those classified as IC/A2-Ca/A2+ (median OS, 378 vs. 1,120 days; HR, 2.99; $95 \%$ CI, 1.22-13.63; $p=0.0269$, Fig. 5c). Almost half of the patients classified as IC/A2+ experienced recurrence within 1 year after R0 resection, even during the course of adjuvant chemotherapy. Interestingly, overall survival showed minor significant difference in three groups and median survival was 633 days in IC/A2+ and 1,398 days in IC/A2- with adjuvant chemotherapy (Fig. 6c). We suppose that the number of patients was too small to show a statistical difference in this study. Even for a high-risk patient, second or third line chemotherapy was effective in IC/A2+ patients.

Prognostic factors including IC/A2

Univariate analysis showed that IC/A2 $+(p=0.012)$, T3T4 $(p=0.048)$, and pathological stage $(p=0.003)$ were significant prognostic factors. In multivariate analysis, IC/ $\mathrm{A} 2+(\mathrm{HR}, 2.550 ; 95 \% \mathrm{CI}, 1.278-5.090 ; p=0.008)$ and pathological stage (HR, 1.390; $95 \%$ CI, 1.080-1.788; $p=0.010$ ) remained independently prognostic (Supplementary Table 3 ). Correlations between the expression of EphA2 and clinicopathological variables are shown in Supplementary Table 2. Overexpression of EphA2 in IC was independent of other factors.

\section{Discussion}

EphA2 is highly expressed in a variety of cancers, including breast, lung, prostate, urinary bladder, ovarian, esophageal, pancreatic, and colorectal cancers [17-24]. Overexpression of EphA2 is associated with tumor progression or poor patient survival. Recently, overexpression of EphA2 or A4 was also reported to be associated with poor prognosis in patients with gastric cancer [25]. We observed expression of EphA2 in cancer cells from 65 of $107(60.7 \%)$ patients with gastric cancer, suggesting that EphA2 may be a good molecular target in gastric cancer, 
Fig. 3 Intermingling of scattered cancer cells and GCSC expressing Ephrin A2 receptors (IC/A2+).

Immunohistochemistry analyzed phenotype of IC/A2positive lesion. a Hematoxylineosin staining of ICs, showing intermingling of scattered cancer cells and stromal cells in invasive lesions. b EphA2 expression in both of cancer cells and stromal cells.

Expression of keratin (c) and vimentin (d) in cancer cells and mesenchymal cells. Fibroblasts, endothelial cells, and hematopoietic cells were positive for vimentin, but negative for keratin. e alphaSMA expression in vascular vessels and myofibroblasts. Most stromal cells were alphaSMA negative in ICs. Large spread stromal cells were positive for alpha-SMA (asterisks), whereas other most small stromal cells in ICs were alpha-SMA negative. f CD31 was expressed in endothelial cells and hematopoietic cells, not in most stromal cells (g) D240 expression in lymphatic endothelial cells. $\mathbf{h}$ Expression of EphA2 in the soma of Auerbach's plexus (black arrow heads). Original magnification $\times 40$
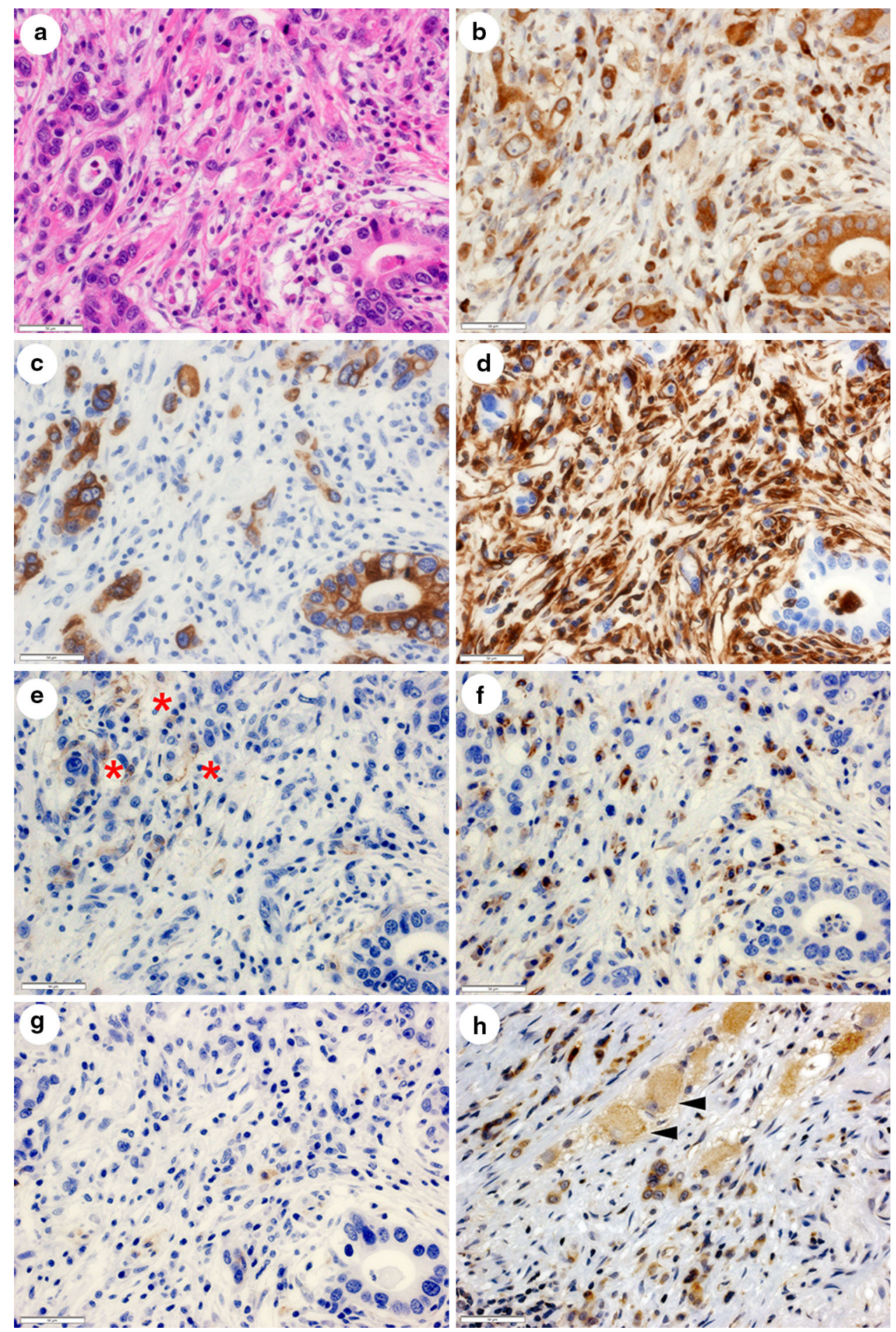

but that EphA2 expression alone is insufficient to distinguish patients at high risk of tumor recurrence. In contrast, IC/A2 + was significantly predictive of relapse. Of 26 patients classified as IC/A2+, $14(53.8 \%)$ developed recurrence, including eight with peritoneal metastasis, three with LN metastasis, and three with blood-borne metastasis, with a median RFS of 378 days, significantly shorter than in patients classified as IC/A2-Ca/A2(1,298 days) or IC/A2-Ca/A2+ (1,120 days). Invisible/ micro-metastases may have been present in IC/A2+ patients at the time of gastrectomy. These patients require another treatment strategy, since many relapsed while receiving adjuvant chemotherapy. Even for a high-risk patient, second or third line chemotherapy was effective in 


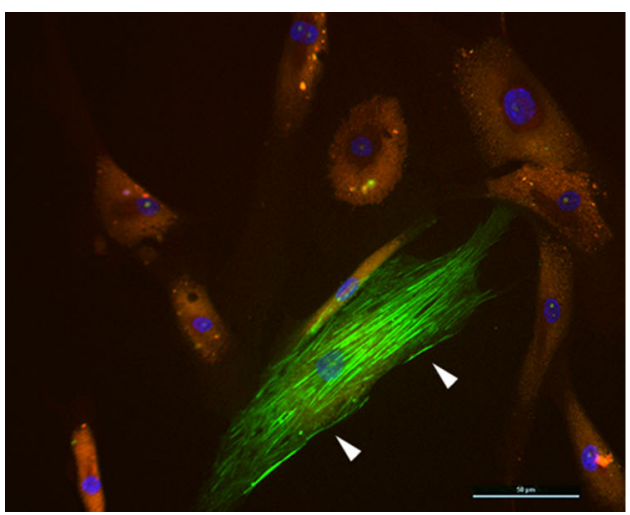

Fig. 4 Immunofluorescent microscopy of primary cultured GCSC. Expression of EphA2 (red) and $\alpha$-SMA (green) was analyzed in primary cultured GCSC by immunofluorescent microscopy. In left panel, GCSC looks EphrinA2-positive (red) and one cell strongly expressed $\alpha$-SMA (white arrow head). In right panel, all cells were
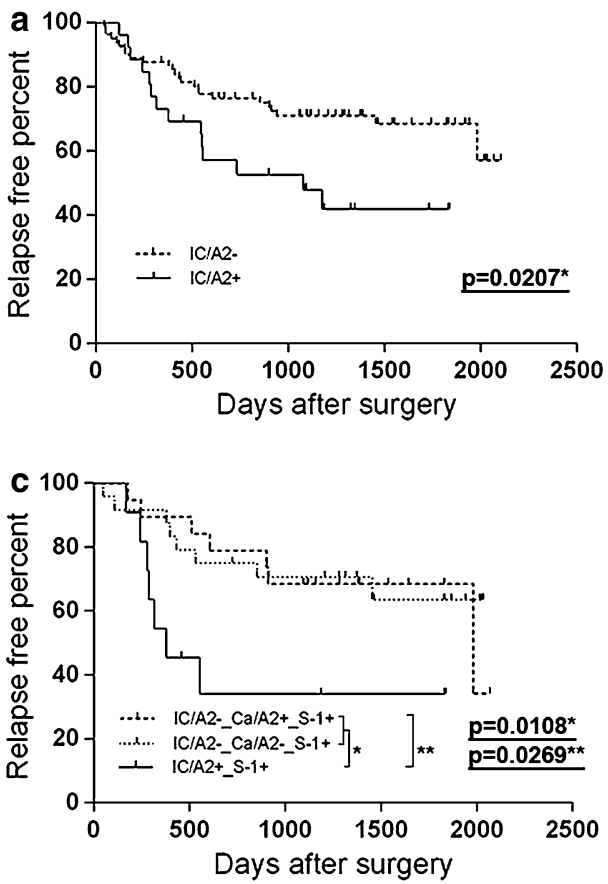

Fig. 5 Relapse free survival of all patients $(n=107)$ and of patients who received adjuvant chemotherapy (S-1, $n=54)$. Kaplan-Meier curves showing the relationship between RFS and expression of EphA2 in IC parts (a), in cancer cells (b) in all patients, and in patients who received adjuvant chemotherapy (c, IC/A2+ vs. IC/A2$\mathrm{Ca} / \mathrm{A} 2 \pm$ vs. $\mathrm{IC} / \mathrm{A} 2-\mathrm{Ca} / \mathrm{A} 2-; \mathbf{d}, \mathrm{Ca} / \mathrm{A} 2)$. a The relapse rate was significantly higher in IC/A2 + than in IC/A2 - patients (HR, 2.12; $95 \%$ CI, $1.16-5.41 ; p=0.0207)$. b The recurrence rate was higher in patients classified as $\mathrm{Ca} / \mathrm{A} 2+$ than in those classified as $\mathrm{Ca} / \mathrm{A} 2-[\mathrm{HR}$, 1.96; $95 \%$ confidence interval $(\mathrm{CI}), 0.99-3.51 ; p=0.0542]$, not significant. c IC/A2 + was significantly associated with poorer RFS during adjuvant chemotherapy (HR, 3.00; $95 \% \mathrm{CI}, 1.47-17.03$;

IC/A2+ patients. Overall survival wasn't significantly different between IC/A2 and $\mathrm{Ca} / \mathrm{A} 2$ without regard for adjuvant chemotherapy. When cancer was relapsed, most

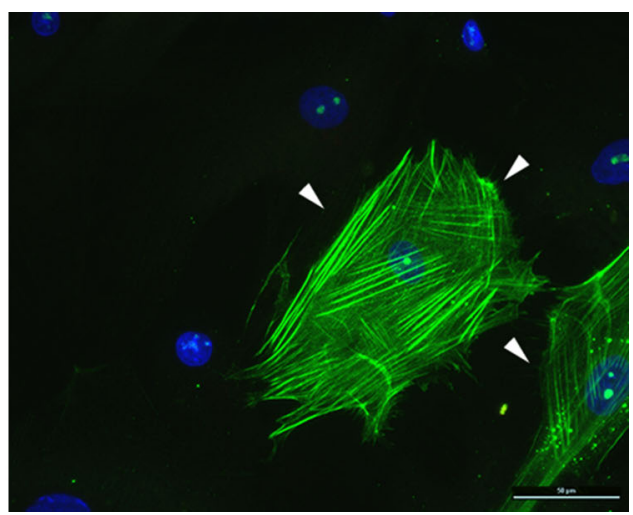

EphA2 negative and widespread cells were $\alpha$-SMA-positive (white arrow head). Primary cultured GCSC expressed different levels of $\alpha$ SMA. These data suggested that the status of GCSC in IC/A2+ might be different from that in cultured and activated myofibroblasts. Original magnification $\times 40$ (color figure online)
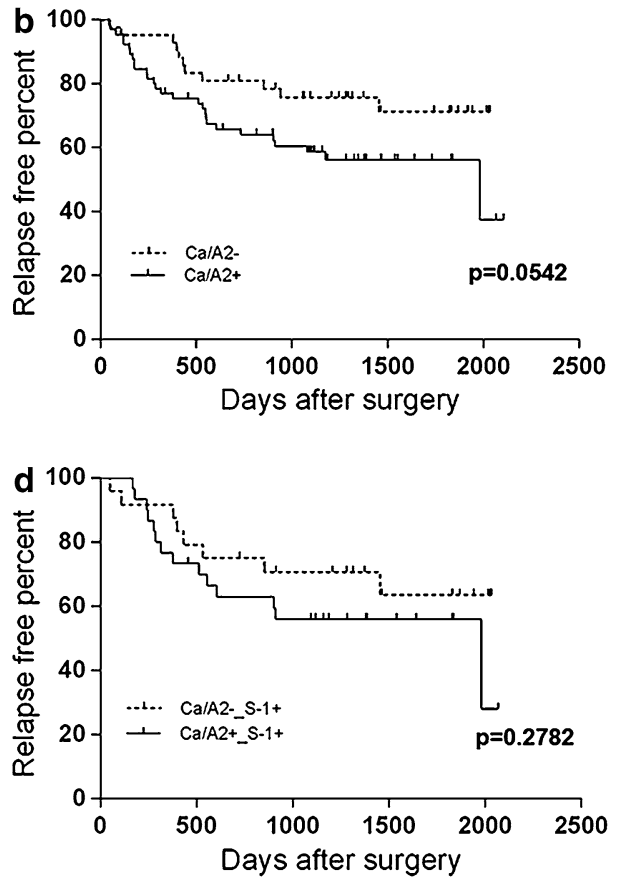

$p=0.0108)$. Stromal reaction may have been prognostic, because patients classified as IC/A2+ had significantly reduced median RFS compared to those classified as IC/A2- (378 vs. 1,120 days; HR, 2.99; $95 \%$ CI, 1.22-13.63; $p=0.0269)$. c, and d Fifty-four patients received six to eight cycles of adjuvant chemotherapy with S-1 (tegafur-gimeracil-oteracil potassium) without severe adverse effects. b Fourteen of 30 patients $(46.7 \%)$ classified as $\mathrm{Ca} / \mathrm{A} 2+$ experienced recurrence during treatment, compared with seven of 11 $(63.6 \%)$ IC/A2 + patients. Almost half of the patients classified as IC/ $\mathrm{A} 2+$ relapsed within 1 year after R0 operation, even while receiving adjuvant chemotherapy

patients received additional chemotherapy, and our data proved effectiveness of additional chemotherapy in relapse cases. IC/A2 + in gastric cancer exactly indicated a risk of 

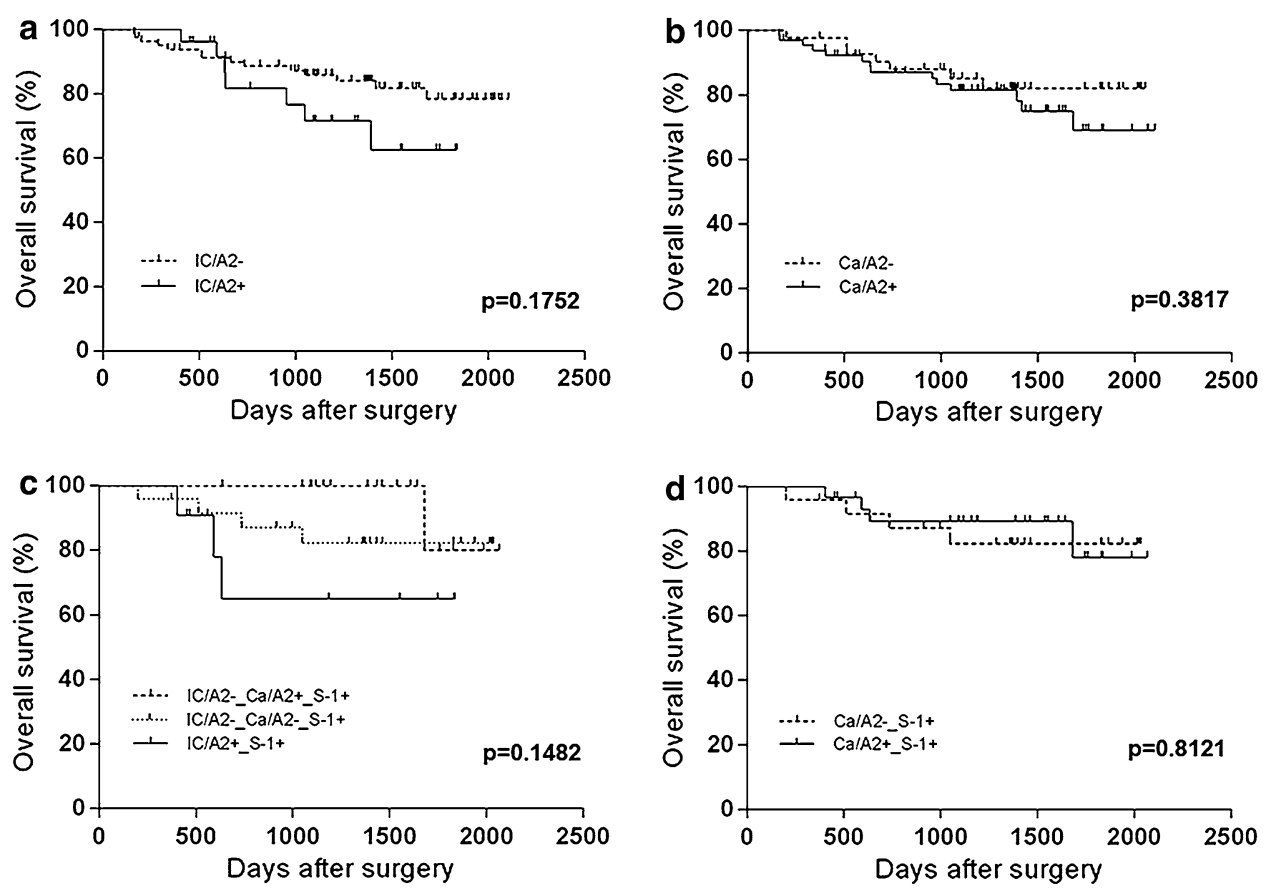

Fig. 6 Overall survival of all patients $(n=107)$ and of patients who received adjuvant chemotherapy (S-1, $n=54)$. Kaplan-Meier curves showing the relationship between overall survival (OS) and expression of EphA2 in IC parts (a), in cancer cells (b) in all patients, and in patients who received adjuvant chemotherapy (c, IC/A2+ vs. IC/A2$\mathrm{Ca} / \mathrm{A} 2 \pm$ vs. IC/A2- $\mathrm{Ca} / \mathrm{A} 2-; \mathbf{d}, \mathrm{Ca} / \mathrm{A} 2)$. a, and b Overall survival wasn't significant in IC/A2 + and IC/A2 - patients $(p=0.1752)$, and in $\mathrm{Ca} / \mathrm{A} 2+$ and $\mathrm{Ca} / \mathrm{A} 2-$ patients $(p=0.3817)$. c Median overall

relapse, not the biological aggressiveness of cancer. In patients who received adjuvant chemotherapy, median RFS and median OS in IC/A2+ was 378 and 633 days. However, median RFS and median OS in IC/A2- was 1,280 and 1,398 days, respectively. Our data indicated that careful follow-up and earlier diagnosis of relapse might improve survival of high-risk patients.

The EphA2-ephrin signaling axis regulates multiple events critical for the malignant transformation of normal cells. The key downstream molecules in this signaling pathway include the phosphatidylinositol $3^{\prime}$ kinases, Src family kinases, Rho and Racl GTPases, mitogen activated protein kinases and integrins. Moreover, there is cross talk between these molecules and other oncogene receptors (e.g., EGFR), which regulate cell adhesion, proliferation, and migration; modulate the cytoskeletal architecture, and control the development of vascular networks. The ephrin RTKs and their ephrin ligands have intriguing expression patterns in cancer and stromal cells, suggesting the importance of their bidirectional signals in many aspects of tumor development and progression. Targeting EphA2 overexpression may be beneficial in cancer therapeutics. Among the molecules targeting Eph receptors and ephrin currently in development are RTKs in the forward

survival in IC/A2+ (633 days) was shorter than in IC/A2(1,398 days), and not significant. d Ca/A2 wasn't a prognostic factor in patients who received adjuvant chemotherapy $(p=0.8121)$. When cancer was relapsed, most patients received additional chemotherapy, and these data had also proved effectiveness of second or third line chemotherapy in relapse cases. IC/A2+ in gastric cancer exactly indicated a risk of relapse, not the biological malignancy of cancer

signaling pathway [26, 27], siRNA/oligonucleotides as inhibitors of Eph expression [28, 29], peptides/mAb that inhibit Eph-ephrin interactions [30, 31], cytotoxic mAbs and $\mathrm{mAb}$ conjugates $[32,33]$, and nanoparticles/mAb as imaging agents [34-36]. Most of these molecules were found to target cancer cells but not stromal cells, and their effects on tumor progression involving cancer stromal cell interactions were unclear. These interactions through the Eph-ephrin axis may be flexible and adaptable for survival in various microenvironments. EphA2 targeting should regulate deleterious cancer stromal cell interactions and be cytotoxic to cancer cells.

In conclusion, IC/EphA2 expression in invasive parts of tumors was useful in determining a high risk of relapse after curative (R0) surgery for gastric cancer. Further examination of the EphA2-ephrin signaling pathway in cancer stromal cells is essential in the development of agents that target Eph and ephrin.

Acknowledgments The authors thank Prof. Kenji Nakanishi, who provided continuing support and constant encouragement throughout this project. We also thank Yuko Yasui of the Department of Surgery, and Nobuyuki Adachi and Ryota Shinozaki of the HCM Joint-Use Research facilities for technical contributions. This work was supported in part by a Grant-in-Aid for Scientific Research 
(C) 25460466, Grant-in-Aid for Researchers, Hyogo College of Medicine, 2012, to Shojiro Kikuchi; a Ministry of Education, Culture, Sports, Science and Technology of Japan-Supported Program for the Strategic Research Foundation at Private Universities, 2012-2015 and a Grant-in-Aid for Scientific Research (C) 23591949 to Mitsuru Sasako; and a grant from the Third-Term Comprehensive Control Research for Cancer conducted by the Ministry of Health, Labour and Welfare of Japan, and Charitable Trust Laboratory Medicine Foundation of Japan to Mitsuru Sasako.

Conflict of interest None of the authors had any financial interests or potential conflicts of interest.

\section{References}

1. Cunningham D, Starling N, Rao S, Iveson T, Nicolson M, Coxon $\mathrm{F}$, et al. Capecitabine and oxaliplatin for advanced esophagogastric cancer. N Engl J Med. 2008;358(1):36-46.

2. Koizumi W, Narahara H, Hara T, Takagane A, Akiya T, Takagi $\mathrm{M}$, et al. S-1 plus cisplatin versus S-1 alone for first-line treatment of advanced gastric cancer (SPIRITS trial): a phase III trial. Lancet Oncol. 2008;9(3):215-21.

3. Dodelet VC, Pasquale EB. Eph receptors and ephrin ligands: embryogenesis to tumorigenesis. Oncogene. 2000;19(49):5614-9.

4. Ireton $\mathrm{RC}, \mathrm{Chen} \mathrm{J}$. EphA2 receptor tyrosine kinase as a promising target for cancer therapeutics. Curr Cancer Drug Targets. 2005;5(3):149-57.

5. Nakamoto M, Bergemann AD. Diverse roles for the Eph family of receptor tyrosine kinases in carcinogenesis. Microsc Res Tech. 2002;59(1):58-67.

6. Miyazaki T, Kato H, Fukuchi M, Nakajima M, Kuwano H. EphA2 overexpression correlates with poor prognosis in esophageal squamous cell carcinoma. Int J Cancer. 2003;103(5):657-63.

7. Fang WB, Brantley-Sieders DM, Parker MA, Reith AD, Chen J. A kinase-dependent role for EphA2 receptor in promoting tumor growth and metastasis. Oncogene. 2005;24(53):7859-68.

8. Kullander K, Klein R. Mechanisms and functions of Eph and ephrin signalling. Nat Rev Mol Cell Biol. 2002;3(7):475-86.

9. Bhowmick NA, Chytil A, Plieth D, Gorska AE, Dumont N, Shappell S, et al. TGF-beta signaling in fibroblasts modulates the oncogenic potential of adjacent epithelia. Science. 2004;303(5659):848-51.

10. Bhowmick NA, Neilson EG, Moses HL. Stromal fibroblasts in cancer initiation and progression. Nature. 2004;432(7015):332-7.

11. Ding L, Saunders TL, Enikolopov G, Morrison SJ. Endothelial and perivascular cells maintain haematopoietic stem cells. Nature. 2012;481(7382):457-62.

12. Ding ZY, Zou XL, Wei YQ. Cancer microenvironment and cancer vaccine. Cancer Microenviron. 2012;5(3):333-44.

13. Pollard JW. Tumour-educated macrophages promote tumour progression and metastasis. Nat Rev Cancer. 2004;4(1):71-8.

14. Zander CS, Soussi T. Breast-cancer stromal cells with TP53 mutations. N Engl J Med. 2008;358(15):1635 (author reply 6).

15. Patocs A, Zhang L, Xu Y, Weber F, Caldes T, Mutter GL, et al. Breast-cancer stromal cells with TP53 mutations and nodal metastases. N Engl J Med. 2007;357(25):2543-51.

16. Japanese classification of gastric carcinoma. 3rd English edition. Gastric Cancer. 2011;14(2):101-12.

17. Kinch MS, Moore MB, Harpole DH Jr. Predictive value of the EphA2 receptor tyrosine kinase in lung cancer recurrence and survival. Clin Cancer Res. 2003;9(2):613-8.

18. Zelinski DP, Zantek ND, Stewart JC, Irizarry AR, Kinch MS. EphA2 overexpression causes tumorigenesis of mammary epithelial cells. Cancer Res. 2001;61(5):2301-6.
19. Zeng G, Hu Z, Kinch MS, Pan CX, Flockhart DA, Kao C, et al. Highlevel expression of EphA2 receptor tyrosine kinase in prostatic intraepithelial neoplasia. Am J Pathol. 2003;163(6):2271-6.

20. Abraham S, Knapp DW, Cheng L, Snyder PW, Mittal SK, Bangari DS, et al. Expression of EphA2 and Ephrin A-1 in carcinoma of the urinary bladder. Clin Cancer Res. 2006;12(2):353-60.

21. Thaker PH, Deavers M, Celestino J, Thornton A, Fletcher MS, Landen $\mathrm{CN}$, et al. EphA2 expression is associated with aggressive features in ovarian carcinoma. Clin Cancer Res. 2004;10(15):5145-50.

22. Xu F, Zhong W, Li J, Shanshen Z, Cui J, Nesland JM, et al. Predictive value of EphA2 and EphrinA-1 expression in oesophageal squamous cell carcinoma. Anticancer Res. 2005;25(4):2943-50.

23. Mudali SV, Fu B, Lakkur SS, Luo M, Embuscado EE, IacobuzioDonahue CA. Patterns of EphA2 protein expression in primary and metastatic pancreatic carcinoma and correlation with genetic status. Clin Exp Metastasis. 2006;23(7-8):357-65.

24. Kataoka H, Igarashi H, Kanamori M, Ihara M, Wang JD, Wang YJ, et al. Correlation of EPHA2 overexpression with high microvessel count in human primary colorectal cancer. Cancer Sci. 2004;95(2):136-41.

25. Miyazaki K, Inokuchi M, Takagi Y, Kato K, Kojima K, Sugihara $\mathrm{K}$. EphA4 is a prognostic factor in gastric cancer. BMC Clin Pathol. 2013;13(1):19.

26. Choi Y, Syeda F, Walker JR, Finerty PJ Jr, Cuerrier D, Wojciechowski A, et al. Discovery and structural analysis of Eph receptor tyrosine kinase inhibitors. Bioorg Med Chem Lett. 2009;19(15):4467-70.

27. Karaman MW, Herrgard S, Treiber DK, Gallant P, Atteridge CE, Campbell BT, et al. A quantitative analysis of kinase inhibitor selectivity. Nat Biotechnol. 2008;26(1):127-32.

28. Carles-Kinch K, Kilpatrick KE, Stewart JC, Kinch MS. Antibody targeting of the EphA2 tyrosine kinase inhibits malignant cell behavior. Cancer Res. 2002;62(10):2840-7.

29. Duxbury MS, Ito H, Zinner MJ, Ashley SW, Whang EE. EphA2: a determinant of malignant cellular behavior and a potential therapeutic target in pancreatic adenocarcinoma. Oncogene. 2004;23(7):1448-56.

30. Coffman KT, Hu M, Carles-Kinch K, Tice D, Donacki N, Munyon K, et al. Differential EphA2 epitope display on normal versus malignant cells. Cancer Res. 2003;63(22):7907-12.

31. Landen CN Jr, Lu C, Han LY, Coffman KT, Bruckheimer E, Halder $\mathrm{J}$, et al. Efficacy and antivascular effects of EphA2 reduction with an agonistic antibody in ovarian cancer. J Natl Cancer Inst. 2006;98(21):1558-70.

32. Jackson D, Gooya J, Mao S, Kinneer K, Xu L, Camara M, et al. A human antibody-drug conjugate targeting EphA2 inhibits tumor growth in vivo. Cancer Res. 2008;68(22):9367-74.

33. Lee JW, Han HD, Shahzad MM, Kim SW, Mangala LS, Nick $\mathrm{AM}$, et al. EphA2 immunoconjugate as molecularly targeted chemotherapy for ovarian carcinoma. J Natl Cancer Inst. 2009;101(17):1193-205.

34. Cai W, Ebrahimnejad A, Chen K, Cao Q, Li ZB, Tice DA, et al. Quantitative radioimmunoPET imaging of EphA2 in tumor-bearing mice. Eur J Nucl Med Mol Imaging. 2007;34(12):2024-36.

35. Scarberry KE, Dickerson EB, McDonald JF, Zhang ZJ. Magnetic nanoparticle-peptide conjugates for in vitro and in vivo targeting and extraction of cancer cells. $J$ Am Chem Soc. 2008;130(31):10258-62.

36. Scarberry KE, Dickerson EB, Zhang ZJ, Benigno BB, McDonald JF. Selective removal of ovarian cancer cells from human ascites fluid using magnetic nanoparticles. Nanomedicine. 2010;6(3):399-408. 